\title{
Review of Learning in Adulthood: A Comprehensive Guide
}

Margaret Becker Patterson, Research Allies for Lifelong Learning

In its fourth edition, Learning in Adulthood provides foundational information on adult learning as well as new information published since the third edition in 2007. The book, which is nearly 600 pages in length, pulls together a "comprehensive overview and synthesis of what we know about adult learning" (p. x): its context, its learners, what and why they learn, the learning process, new approaches, theory of adult learning, and other relevant issues. The focus is on the needs of the adult learner, how to facilitate their learning, the "technologyinfused context in which learning takes place" (p. x) and how learners interact with the context and with learning itself. Folding in elements of recent research in sociology, philosophy, critical social theory, and psychology, the authors take a multidisciplinary approach in their presentation of the context of learning.
Learning in Adulthood consists of four parts. Part I, "Adult Learning in Contemporary Society" covers the context in which adult learning occurs; Part II, "Adult Learning Theory" covers the theories and models of adult learning; Part III, "Newer Approaches to Adult Learning" and Part IV, "Learning and Development" cover topics that intersect with adult learning. Each part consists of 3-5 chapters, described in detail in the book's preface. The book includes something for readers whose levels of expertise vary, including both new adult educators and those wellversed in adult education research. The authors present the book as reading material for adult education courses and professional development for practitioners as well as a resource for adult education researchers.

The book is well organized topically, and each chapter concludes with a useful one-page 
summary encompassing the chapter's major points and takeaways. For example, Chapter 10 introduces five perspectives from around the globe: Confucianism, Hinduism, Maori, Islam, and African indigenous knowledge. In addition to the authors' introduction and identification of themes, they present five essays explaining nonU.S. perspectives from guest authors well-versed in respective traditions and perspectives on adult education; these essays bring perspectives alive. This chapter helpfully summarizes the "value of engaging with other frameworks" and notes the challenge of thinking "about the purpose of education and learning" outside Western traditions (p. 288).

This fourth edition retains much of the chapter structure and content from the third edition yet differs from the third in several meaningful ways. The authors updated their examples and research findings from more recent studies throughout each chapter. Although the book still encompasses 16 chapters, the third edition's $11^{\text {th }}$ chapter, which reviewed five traditional learning theories (behaviorism, humanism, cognitivism, social cognitive learning, and constructivism), has been removed.

A new Chapter 2 has been added to cover adult learning and technology. The chapter focuses on the history of distance learning, theories of online learning, and technology's role in non-formal learning (i.e., learning that occurs in organizations outside of formal education settings) and informal learning (i.e., any learning that occurs outside a formal context and outside organizations). The authors note that "technology is both creating learning demands and facilitating learning in adult life," (p. 2) a statement that has special importance due to the impact of the coronavirus pandemic on adult learning and instruction.
Learning in Adulthood lives up to its subtitle of being a comprehensive guide. The authors present a vast amount of information in a clear and informative writing style. Arguments are thoroughly cited. And with approximately 80 pages of references, what is not covered in each chapter is readily available through these references.

My only criticism of the book centers around the inconsistent quantity and quality of use of tables, figures, and graphics. Offering a reader tables, figures, or other graphics around long stretches of narrative is a time-tested technique to keep the reader engaged. Multiple chapters feature occasional tables and graphics, but these features diminish as the book goes along. Features are somewhat simple or even challenging to read, appear to present mostly older theories, ideas, or outdated statistics and could be substantially more engaging. For example, a figure in Chapter 3 displayed seven hexagons in a figure of a model, but the hexagons and print are nearly the same shade, making the print very hard to interpret. Tables tend to be formatted with little spacing, making it difficult to differentiate rows. In another example, Table 4.1 in Chapter 4 offers a two-page table with statistics on adult participation, yet the statistics are very out of date (from 2004-2005) so no longer particularly informative. All three chapters in Part III feature only one figure. No figures or tables are employed in Part IV. This loss of potential to engage readers, particularly students, is unfortunate.

In conclusion, this book appears intended as a text for an introductory adult learning course and is helpfully divided into a chapter for each week of a standard 16-week semester. Professors and lecturers may find it useful as a main course text, to be supplemented by additional newer resources. It is also a useful reference for adult educators and researchers who want to know more about 
adult theory, or who need a solid grounding before delving deeper into a specific topic. The main value is in its breadth of topics and pointing readers to where they could get more information. It is a full 40 pages longer than the third edition, and 23 of those additional pages are dedicated to more references and indexing at the end of the book. As a reference work, it touches on major theories of adult learning and practice, primarily from a historical perspective. Although the book is updated in most of its chapters, except for the new Chapter 2, it does not read like a particularly current resource. For readers wanting to ponder the latest scholarship, without hunting aimlessly through Google Scholar, ResearchGate, or a university electronic database, it provides a good launching point. 